\title{
Characterization of the performance of venturi-based aeration devices for use in wastewater treatment in low-resource settings
}

\author{
Jean-David Therrien ${ }^{1 *}$, Peter A Vanrolleghem ${ }^{1}$ and Caetano C Dorea ${ }^{1,2}$ \\ 'Département de Génie Civil et de Génie des Eaux, 1065, Avenue de la Médecine, Université Laval, Québec, QC, G1V OA6, Canada \\ ${ }^{2}$ Department of Civil Engineering, University of Victoria, Victoria, BC, V8W 2Y2, Canada
}

\begin{abstract}
Low-cost aerators relying on the venturi principle to entrain air into flowing water have the notable advantage of contributing both to water mixing and oxygen transfer, making them attractive for wastewater treatment in low-resource settings. This study aimed to characterize the performance of such aerators by describing the impact of different design characteristics, including water flow rate, the number of nozzles used, and the nozzle depth. The study also explored the effect on aeration performance of temperature, total dissolved solids (TDS) concentration, and addition of the archetypal surfactant sodium dodecyl sulphate (SDS). Tests were conducted in a $200 \mathrm{~L}$ reactor with 2,3 or 4 nozzles, at depths of 20,40 or $60 \mathrm{~cm}$, while circulating water through the aeration device at a rate of 400,600 or $800 \mathrm{~L} / \mathrm{h}$. The configuration that yielded the highest mass transfer coefficient $\left(K_{\mathrm{L}} a_{20}\right.$ of $\left.20.8 \mathrm{~h}^{-1}\right)$ had both the highest flow rate $(800 \mathrm{~L} / \mathrm{h})$ and the smallest number of nozzles (2). Nozzle depth had no detectable effect on performance. The configuration with the highest standard aeration efficiency (SAE) had a low flow rate $(400 \mathrm{~L} / \mathrm{h})$ and 4 nozzles. The effect of TDS concentration was not detected in the concentration range typical of domestic wastewater $(300-1250 \mathrm{mg} / \mathrm{L})$. The effect of temperature on $K_{\mathrm{L}} a$ followed a first-order exponential curve, as reported in the literature $(\theta=1.02)$. Addition of SDS was found to increase the $K_{\mathrm{t}} a_{20}$ of the tested aerator design by up to $60 \%$ of its value in tap water, in contrast to results from literature. The performance data obtained herein was compared to other types of aerators. Though venturi nozzles were found to be less efficient than other available technologies, it is proposed that using plunging rather than immersed venturi nozzles could increase performance to an attractive level for low-resource applications.
\end{abstract}

Keywords: aeration, wastewater treatment, low-resource, venturi, water quality, oxygen transfer

\section{INTRODUCTION}

Aeration is a fundamental component of aerobic biological wastewater treatment, as it allows microorganisms to populate the wastewater and consume unwanted pollutants. Common aeration technologies include bubble diffusers, which use compressed air to produce large numbers of bubbles inside reactors, and mechanical aerators, which disturb the water surface and entrain air bubbles into the bulk of the process water. In both cases, the goal is to increase the oxygen mass transfer rate by increasing the air-water interfacial area, which is where oxygen transfer occurs. Those two technologies require heavy equipment to function (air compressors for bubble diffusers, motors and mechanical components for surface aerators). Reactors fitted with bubble diffusers may also need to supplement their reactor design with mechanical mixers to ensure sufficient mixing for aerobic wastewater treatment. The reliance on such bulky and expensive devices is a problem in low-resource areas where the availability of service parts or qualified maintenance workers is difficult to guarantee. Those issues make the aeration of wastewater impractical in remote areas or in developing countries. Alternative aeration technologies could help alleviate those problems. For instance, aeration through a device making use of the venturi principle is an interesting option, as it is relatively cheap, requires few mechanical parts (only a pump is required), and creates both the air bubbles and the mixing required for aerobic wastewater treatment.

\footnotetext{
* To whom all correspondence should be addressed
} e-mail: jean-david.therrien.1@ulaval.ca

Received 13 June 2018, accepted in revised form 7 March 2019.
Several authors have already explored the potential of venturi aeration. Bagatur (2005) investigated the aeration performance of water jets with varying nozzle shapes, and found that venturi nozzles with air inlet holes had the highest aeration efficiency among different types of plunging jets. Venturi aeration has also been investigated as an alternative to mechanical aeration in aerated lagoons with promising results for odour reduction (Mukhtar et al., 2010). However, questions remain as to what factors must be considered when designing venturi-based aerators. Dong et al. (2012) have provided some answers to this problem by demonstrating that venturi nozzles connected in parallel have a higher aeration efficiency than nozzles connected in series, and by describing changes in aeration efficiency when the venturi nozzles were placed at different depths inside the water column.

In later work, Bagatur and Onen (2014) developed a nonlinear model predicting the air entrainment rate of nozzles accounting for the nozzle throat diameter, liquid jet flow rate, jet length, nozzle diameter and jet impact angle. However, this study used circular water jets instead of venturi nozzles. Additionally, air entrainment rate cannot by itself predict aeration performance, as the latter is also affected by bubble size, velocity and residence time, as well as by the characteristics of the water matrix in which the aeration is taking place (Painmanakul et al., 2005). Among the properties of the water matrix known to affect aeration performance, the presence of sodium dodecyl sulphate (SDS), an archetypal surfactant, is of note, as well as the concentration of total dissolved solids (TDS) (Linek et al., 1987; Mancy and Okun, 1960).

The present study therefore set out to investigate the performance of various design variations of a venturi-based aeration device in water with varying properties. This device consisted of venturi nozzles submerged in water and connected in parallel to a vane pump. After determining which design 
yielded the most effective aeration, the latter design was used for aeration of the reactor, while characteristics of the test water were modified to investigate the variation of aeration performance with changes to the water matrix.

\section{METHODS}

\section{Experimental setup}

The tests were carried out inside a reduced-scale reactor filled with tap water. The reactor consisted of a $200 \mathrm{~L}$ cylindrical water tank $80 \mathrm{~cm}$ in height and $60 \mathrm{~cm}$ in diameter. A schematic drawing of the experimental setup can be found in Fig. 1 .

In the first section of the experiment, the impact of changes in the water flow rate through the aeration device $Q$, the vertical distance $D$ between the mouth of the venturi nozzles and the surface, and the number of nozzles operating in parallel $\mathrm{N}$, were investigated. The aeration apparatus used to test those configurations consisted of a 4-port manifold, which was fitted with 2, 3 or 4 venturi nozzles (Mazzei model 284, USA). Unused ports were fitted with a stopper. The apparatus was connected to a Fluid-o-Tech $1 / 2$ hp vane pump (model PO-1000, Italy), which circulated the test water through the aeration device and back into the tank. The flow rate through the aeration device was controlled with 2 valves which diverted excess water into a derivation branch built into the circulation loop. The ratio of pump power to water volume used in this experiment is comparable to what can be found in full-scale pond aeration systems such as the one described in Ghernaout et al. (2018).

The loop included a rotameter and a manometer to monitor the water flow rate and the pressure directly upstream of the injector device. Each venturi nozzle's air intake port was also connected to a rotameter to measure the aspiration rate. A heating and cooling coil was used to control temperature.

Conditions inside the reactor were recorded using an IntelliCAL LDO101 (Hach, USA) dissolved oxygen (DO) probe and an IntelliCAL CDC401 (Hach, USA) conductivity probe connected to a Hq40d data logger (Hach, USA).

\section{Experimental method}

Aeration performance was measured according to the ASCErecommended method (ASCE, 2006). A solution of reagentgrade sodium sulphite (Sigma-Aldrich, USA) and a catalyst solution of cobalt chloride (Sigma-Aldrich, USA) were used to strip the test water of oxygen before each test. The aeration device was then turned on, and DO levels were recorded every 30 s during re-aeration. Water and air flow rates, as well as water pressure, were monitored and recorded every $5 \mathrm{~min}$.

The aeration device was kept in operation at least until DO concentration had reached $98 \%$ or more of the theoretical saturation level, which was calculated automatically by the LDO101 probe based on temperature and atmospheric pressure. The test water was discarded and replaced with fresh tap water after 2 consecutive additions of sodium sulphite to maintain similar water matrix characteristics across different tests.

\section{Evaluation of performance}

The volumetric transfer coefficient $K_{\mathrm{L}} a$ was calculated using the DOPar 3.0.3 software bundle recommended by the ASCE (Stenstrom, 2012). This software bundle applies a non-linear regression algorithm to the DO measurements taken during re-aeration of the test water to estimate the parameters found

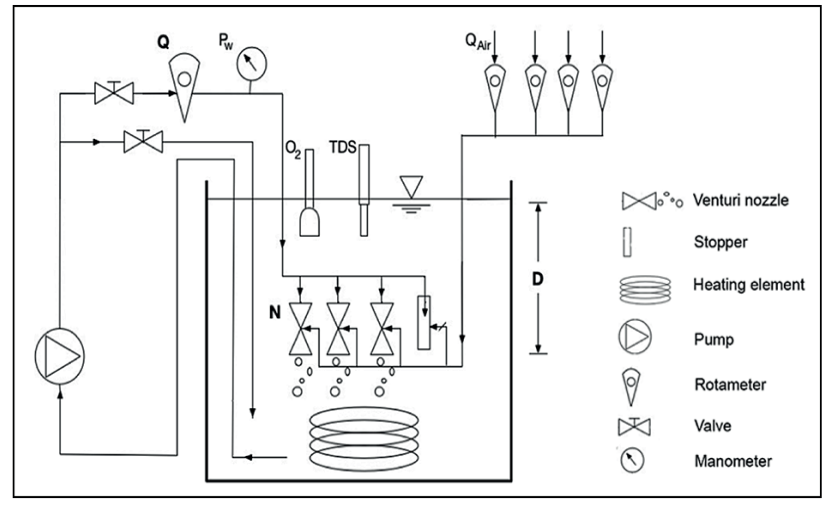

Figure 1

Schematic of experimental setup

in Eq. 1: the DO saturation concentration $C_{\infty}^{\star}$; the intercept of the re-aeration curve $C_{0}$; and the volumetric transfer coefficient $K_{\mathrm{L}} a$.

$$
C(t)=C^{*} \infty-\left(C^{*} \infty-C-{ }_{0}\right) \cdot e^{-K_{L} a \cdot t}
$$

To compare different test results, the value of $K_{\mathrm{L}} a$ obtained using non-linear regression must be corrected to standard conditions (temperature $T=20^{\circ} \mathrm{C}$ ). This correction is performed using Eq. 2, where the recommended value for $\theta$ is 1.024 (ASCE, 2006).

$$
K_{L} a_{20}=K_{L} a \theta^{20-T}
$$

While $K_{\mathrm{L}} a_{20}$ allows for the comparison of the relative speed of oxygen transfer, it is not the most appropriate way to describe the efficiency of aeration based on the total volume of air entrained or based on energy input. Since this information could be highly pertinent in contexts where energy is in short supply or cost-prohibitive, this study also uses standard oxygen transfer rate (SOTR), standard oxygen transfer efficiency (SOTE) and standard aeration efficiency (SAE) as additional metrics to describe aeration performance. However, given the small scale of this study's experimental setup, the resolution of values output by DOPar for those parameters was sometimes limited to just one or two significant digits. Examples of such low-resolution outputs for some of this study's preliminary runs are shown in Table 1 . These tests were conducted using conditions similar to those described in Table 3. For the sake of precision, SOTE, SOTR and SAE were therefore recalculated manually using Eqs 3-7, which are described below.

SOTR is calculated using Eq. 3, where $V$ represents the volume of water inside the reactor. represents the saturation

TABLE 1

Examples of DOPar outputs with low resolution

\begin{tabular}{|l|c|c|c|}
\hline Example & SOTR $(\mathbf{k g} / \mathbf{h})$ & SOTE $(\%)$ & SAE $(\mathbf{k g} / \mathbf{k W h})$ \\
\hline A & 0.01 & 9.45 & 0.40 \\
\hline B & 0.01 & 8.89 & 0.50 \\
\hline C & 0.01 & 9.52 & 0.09 \\
\hline D & 0.02 & 9.65 & 0.13 \\
\hline E & 0.02 & 9.81 & 0.30 \\
\hline
\end{tabular}


DO concentration in the water at standard conditions and was calculated by DOPar.

$$
\text { SOTR }=K_{L} a_{20} C_{\infty 20}^{*} V
$$

SOTE was calculated using Eq. 4, where $\mathrm{WO} 2$ represents the mass flow of oxygen entering the water during reaeration, which is calculated with Eq. 5, where i represents the number of venturi jet nozzles connected to the aeration apparatus.

$$
\begin{gathered}
\text { SOTE }=S O T R / W_{\mathrm{O} 2} \\
W_{\mathrm{O} 2}=\sum_{i=1}^{4} Q_{\mathrm{air}, \mathrm{i}} \cdot 1.20 \frac{\mathrm{kg}}{\mathrm{m}^{3} \text { air }} \cdot 0.23 \mathrm{~kg}_{\mathrm{O} 2} / \mathrm{kg}_{\mathrm{air}}
\end{gathered}
$$

SAE was calculated using Eq. 6 . The power input measurement used to calculate SAE was the hydraulic power, which is calculated using Eq. 7, where $P_{\text {w }}$ represents the relative pressure inside the loop directly upstream from the aeration device. It must be noted that Eq. 7 calculates the net hydraulic power transmitted to the fluid and does not take into account the efficiency of the devices used. This simplification enables one to focus on the venturi nozzles' own aeration efficiency without intertwining it with the efficiencies of the devices upstream, i.e. the pump and its motor.

$$
\mathrm{SAE}=\mathrm{SOTR} / \text { Power Input }
$$

Power Input $=Q \cdot P w$

\section{Experimental design}

The investigated range of aeration device configurations is shown in Table 2. These configurations are characterized by the number $N$ of nozzles connected to the device, the water flow rate $Q$ passing through the device, and the depth of immersion $D$. Each of those characteristics was tested at 3 different levels. A subset of $3^{2}$ combinations of factors out of the possible $3^{3}$ was selected for testing using a partial factorial experimental design (Box, 2005), which was generated using the rsm package in $R$ (Lenth, 2010; R Development Team, 2016). The generated combinations of $N, Q$ and $D$ are presented in Table 3. Those combinations were tested in a randomized sequence, and the tests were replicated in 2 discrete runs of tests performed in different sequences. The resulting data were used to generate surface response curves using the $r s m$ package. These response curves described the evolution of the 4 performance indicators with changes in $N, Q$ and $D$.

\section{Modifications to the water matrix}

Table 4 shows the levels of temperature, TDS concentration and SDS concentration at which aeration performance was measured. Each water matrix variable was tested independently. The aeration device design selected to perform those tests was the one which yielded the highest $K_{\mathrm{L}} a_{20}$ in the aerator design section of this study.

In its guidelines, the ASCE (2006) suggests a correction factor to account for the effect of TDS on aeration. This correction is described by Eq. 8 . However, the application of this correction factor is optional in the latest version of the guidelines. The effect of TDS on the aeration performance
TABLE 2

Levels of tested design factors

\begin{tabular}{|l|c|c|c|}
\hline Variable & Level 1 & Level 2 & Level 3 \\
\hline$N(-)$ & 2 & 3 & 4 \\
\hline$Q(\mathrm{~L} / \mathrm{h})$ & 400 & 600 & 800 \\
\hline$D(\mathrm{~m})$ & 0.2 & 0.4 & 0.6 \\
\hline
\end{tabular}

\begin{tabular}{|l|c|c|c|}
\hline \multicolumn{4}{|c|}{ TABLE 3 } \\
\hline $\begin{array}{l}\text { Cesign } \\
\text { configuration }\end{array}$ & $\boldsymbol{N}(-)$ & $\boldsymbol{Q}(\mathrm{L} / \mathrm{h})$ & $\boldsymbol{D}(\mathrm{m})$ \\
\hline 1 & 2 & 400 & 0.20 \\
\hline 2 & 2 & 600 & 0.40 \\
\hline 3 & 2 & 800 & 0.60 \\
\hline 4 & 3 & 400 & 0.40 \\
\hline 5 & 3 & 600 & 0.40 \\
\hline 6 & 4 & 400 & 0.60 \\
\hline 7 & 3 & 800 & 0.20 \\
\hline 8 & 4 & 600 & 0.20 \\
\hline 9 & 4 & 800 & 0.40 \\
\hline
\end{tabular}

\begin{tabular}{|l|r|r|r|r|c|}
\hline \multicolumn{7}{|c|}{ TABLE 4 } \\
\hline $\begin{array}{l}\text { Water } \\
\text { characteristic }\end{array}$ & Level 1 & Level 2 & Level 3 & Level 4 & Level 5 \\
\hline TDS (mg/L) & 300 & 1200 & - & - & - \\
\hline $\begin{array}{l}\text { Temperature } \\
\left({ }^{\circ} \mathrm{C}\right)\end{array}$ & 10 & 20 & 30 & - & - \\
\hline SDS $(\mathrm{mg} / \mathrm{L})$ & 0 & 2 & 5 & 8 & 15 \\
\hline
\end{tabular}

was therefore investigated to determine whether this effect was detectable at the concentrations one might expect to find in domestic wastewater (300-1 $250 \mathrm{mg} / \mathrm{L}$ ) (Ali et al., 2012). TDS concentration in the test tank was controlled by the addition of a solution of sodium chloride (Sigma-Aldrich, USA).

$$
K_{\mathrm{L}} a_{1000 \mathrm{mg} / \mathrm{L}}=K_{\mathrm{L}} a \cdot e^{[0.0000965(1000-\mathrm{TDS})]}
$$

The effect of the addition of SDS was investigated by adding a volume of concentrated SDS solution (Sigma-Aldrich, USA) to the test water before deoxygenation. Since surfactants are typically minor components of domestic wastewater, concentrations of SDS varying from $0-15 \mathrm{mg} / \mathrm{L}$ were tested in this study.

The water temperature is also widely known to affect the mass transfer rate. Since low-resource areas exist in warm, temperate, and cold regions of the world, the aeration performance was tested at temperatures that reflected the operating conditions of treatment in a wide range of climates $\left(10-30^{\circ} \mathrm{C}\right)$ (Sabry, 2010; Yates et al., 2012). This temperature range was selected as it corresponds to the largest range of temperatures at which the available heating and cooling device could operate effectively with this experiment's reactor volume. 


\section{Modelling the effects of the design factors on aeration}

The test data collected during the experiments outlined in Table 3 were used to generate first- and second-degree polynomial response surface curves for $K_{L} a_{20^{\circ}} S O T R$, SOTE and SAE. Those curves were generated following a model of the form shown in Eq. 9 (Box, 2005):

Response $=a_{0}+a_{1} Q+a_{2} N+a_{3} D+a_{4} Q N+$

An analysis of variance was performed on the terms of the model $(\alpha=5 \%)$. In the case where the $p$-value associated with a coefficient $a_{i}$ was larger than $\alpha$, the term containing that coefficient was removed, and the model was re-generated. Second-order terms were only added to the model if a lack-of-fit test showed that a first-order model did not adequately describe the response. Moreover, the normality of the residuals of the 4 models was verified using a Shapiro-Wilk test in $R(\alpha=5 \%)(R$ Development Team, 2016), and heteroscedasticity was verified visually (Box, 2005).

\section{Modelling the effect of changes to the water matrix}

The $\theta$ factor was determined by fitting the data of aeration tests performed at different temperatures to the first-order kinetics described by Eq. 2. This fitting was performed using a least-squares non-linear regression (Box, 2005; R Development Team, 2016).

The effect of TDS was evaluated using aeration tests performed at the lowest and highest boundaries of the TDS concentrations of interest for domestic wastewater. The test results were then grouped in accordance with their relative
TDS concentration (low or high), and a t-test was performed to determine whether the 2 groups had significantly different mean responses $(\alpha=5 \%)$ (Box, 2005).

Aeration tests were performed in tap water containing different concentrations of SDS. Several researchers have developed non-linear models for the effect of SDS on aeration (Eckenfelder et al., 1956; Mancy and Okun, 1960; Painmanakul et al., 2005). However, those studies generally did not use jet aeration, focusing instead on bubble diffusers, which means that a model predicting the effect of SDS on jet-powered aeration performance is not readily available in the literature. Therefore, as a primary exploration of the phenomenon, the results of the tests were simply fitted to a linear model of the form described by Eq. 10.

$$
\text { Response }=a_{0}+a_{1} \operatorname{SDS}(\mathrm{mg} / \mathrm{L})
$$

\section{RESULTS AND DISCUSSION}

\section{Result of the design configuration study}

The results of the aeration tests involving the 9 tested aerator designs are presented in Table 5. Attempts to measure the performances of Design 3 failed due to the high flow rate being pushed through a small number of nozzles. This created excessively high pressures within the external loop, which ultimately caused its connections to leak. Tests involving that configuration therefore had to be prematurely stopped to prevent damage to the equipment.

Of the designs whose performance could be measured, the one that yielded the highest $K_{\mathrm{L}} a_{20}$ was Design 6 . This design was therefore chosen to perform the remaining experiments concerning the properties of the water matrix.

\begin{tabular}{|c|c|c|c|c|c|c|c|c|c|}
\hline \multicolumn{10}{|c|}{$\begin{array}{c}\text { TABLE } 5 \\
\text { Aeration performance of } 9 \text { aerator designs }\end{array}$} \\
\hline $\begin{array}{l}\text { Design } \\
\text { configuration }\end{array}$ & Block & $\begin{array}{c}\text { TDS } \\
( \pm 2 \mathrm{mg} / \mathrm{L})\end{array}$ & $\begin{array}{c}T \\
\left( \pm 0.3^{\circ} \mathrm{C}\right)\end{array}$ & $\begin{array}{l}\text { Pw }(k W) \\
\quad \pm 5 \%\end{array}$ & $\begin{array}{l}K_{\mathrm{L}} a_{\text {test }}\left(h^{-1}\right) \\
\pm 15 \%\end{array}$ & $\begin{array}{c}K_{\mathrm{L}} a_{20^{\circ} \mathrm{C}}\left(h^{-1}\right) \\
\quad \pm 15 \%\end{array}$ & $\begin{array}{l}\text { SOTR (kg/h) } \\
\quad \pm 13 \%\end{array}$ & $\begin{array}{l}\text { SOTE (-) } \\
\pm 14 \%\end{array}$ & $\begin{array}{l}\text { SAE (kg/ } \\
\text { kWh) } \\
\pm 13 \%\end{array}$ \\
\hline \multirow[t]{2}{*}{1} & 1 & 291 & 20.4 & 0.048 & 8.2 & 8.1 & 0.015 & 0.11 & 0.31 \\
\hline & 2 & 449 & 20.4 & 0.056 & 8.7 & 8.6 & 0.016 & 0.12 & 0.29 \\
\hline \multirow[t]{2}{*}{2} & 1 & 340 & 20.4 & 0.15 & 14.0 & 13.8 & 0.025 & 0.14 & 0.17 \\
\hline & 2 & 390 & 20.3 & 0.14 & 11.1 & 11.0 & 0.021 & 0.12 & 0.15 \\
\hline \multirow[t]{2}{*}{3} & 1 & NA & NA & NA & NA & NA & NA & NA & NA \\
\hline & 2 & NA & NA & NA & NA & NA & NA & NA & NA \\
\hline \multirow[t]{2}{*}{4} & 1 & 270 & 20.3 & 0.022 & 6.4 & 6.3 & 0.012 & 0.095 & 0.54 \\
\hline & 2 & 395 & 20.4 & 0.024 & 7.1 & 7.0 & 0.013 & 0.10 & 0.56 \\
\hline \multirow[t]{2}{*}{5} & 1 & 314 & 20.2 & 0.073 & 13.9 & 13.8 & 0.026 & 0.13 & 0.35 \\
\hline & 2 & 443 & 20.5 & 0.086 & 14.6 & 14.5 & 0.026 & 0.13 & 0.31 \\
\hline \multirow[t]{2}{*}{6} & 1 & 305 & 20.4 & 0.18 & 22.1 & 21.8 & 0.039 & 0.15 & 0.22 \\
\hline & 2 & 469 & 20.5 & 0.18 & 19.5 & 19.2 & 0.035 & 0.14 & 0.20 \\
\hline \multirow[t]{2}{*}{7} & 1 & 291 & 20.3 & 0.014 & 4.9 & 4.8 & 0.0091 & 0.089 & 0.66 \\
\hline & 2 & 368 & 20.4 & 0.013 & 4.9 & 4.9 & 0.0096 & 9.5 & 0.72 \\
\hline \multirow[t]{2}{*}{8} & 1 & 304 & 20.4 & 0.051 & 11.4 & 11.3 & 0.0208 & 9.7 & 0.41 \\
\hline & 2 & 439 & 20.4 & 0.051 & 11.4 & 11.3 & 0.0208 & 9.8 & 0.41 \\
\hline \multirow[t]{2}{*}{9} & 1 & 442 & 20.3 & 0.12 & 16.3 & 16.2 & 0.0316 & 11.9 & 0.26 \\
\hline & 2 & 310 & 20.4 & 0.13 & 17.6 & 17.4 & 0.0321 & 12.0 & 0.26 \\
\hline
\end{tabular}




\section{Modelling of the performance of aerator designs}

The missing information from Design 3 made it impossible to generate adequate response surface curves using the data as-is. Therefore, the dataset was completed through data imputation using the mice software package in $R$ (Van Buuren and Groothuis-Oudshoorn, 2011). This package generates simulated values for missing data points in factorial designs using chained equations. This imputation comes at the cost of the removal of 1 degree of freedom per imputed point added to the dataset.

The coefficients of the resulting models for $K_{\mathrm{L}} a_{20}$, SOTR, SOTE and SAE are summarized in Table 6, with the correlation coefficient of their respective model and associated $p$-value. Rows containing only null coefficients were omitted from the table.

Table 6 shows that all terms involving injector depth D in Eq. 9 were discarded from the final models, as its effect was not found to be significant. This runs contrary to what was reported in Dong et al. (2012), who found that a depth of 40 $\mathrm{cm}$ was optimal while aerating a lagoon with their venturi device. It is possible that the shallow overall depth of the reactor used in this study, combined with the strength of the water jets, allowed for similar mixing of the water column to occur for all tested depths, which may have drowned out its effect. The 2 remaining test variables, $\mathrm{Q}$ and $\mathrm{N}$, were found to impact aeration performance significantly. The contour curves describing the effect of $\mathrm{Q}$ and $\mathrm{N}$ on the 4 performance indicators are shown in Figs 2-5.

\begin{tabular}{|c|c|c|c|c|}
\hline \multicolumn{5}{|c|}{$\begin{array}{l}\text { TABLE } 6 \\
\text { Response surface model coefficients for } K_{\mathrm{L}} a_{20} \text {, SOTR, } \\
\text { SOTE and SAE }\end{array}$} \\
\hline Coefficient & $K_{L} a_{20^{\circ} \mathrm{C}}\left(\mathrm{h}^{-1}\right)$ & SOTR (kg/h) & SOTE (\%) & $S A E(\mathrm{~kg} / \mathrm{kWh})$ \\
\hline $\mathrm{a}_{0}$ & 4.86 & 0.0083 & 13 & -0.24 \\
\hline$a_{1}(Q)$ & 0.033 & $6.0 \times 10^{-5}$ & 0.0098 & -0.0011 \\
\hline$a_{2}(N)$ & -1.6 & -0.003 & -1.6 & 0.49 \\
\hline$a_{4}(Q \bullet N)$ & 0 & 0 & 0 & -0.0003 \\
\hline$a_{7}\left(Q^{2}\right)$ & 0 & 0 & 0 & $2.0 \times 10^{-6}$ \\
\hline$a_{8}\left(N^{2}\right)$ & 0 & 0 & 0 & -0.04 \\
\hline$p$-value & $<0.001$ & $<0.001$ & $<0.001$ & $<0.001$ \\
\hline$R_{\text {Adjusted }}^{2}$ & 0.94 & 0.94 & 0.81 & 0.98 \\
\hline Lack-of-fit & 0.06 & 0.21 & 0.45 & 0.26 \\
\hline
\end{tabular}

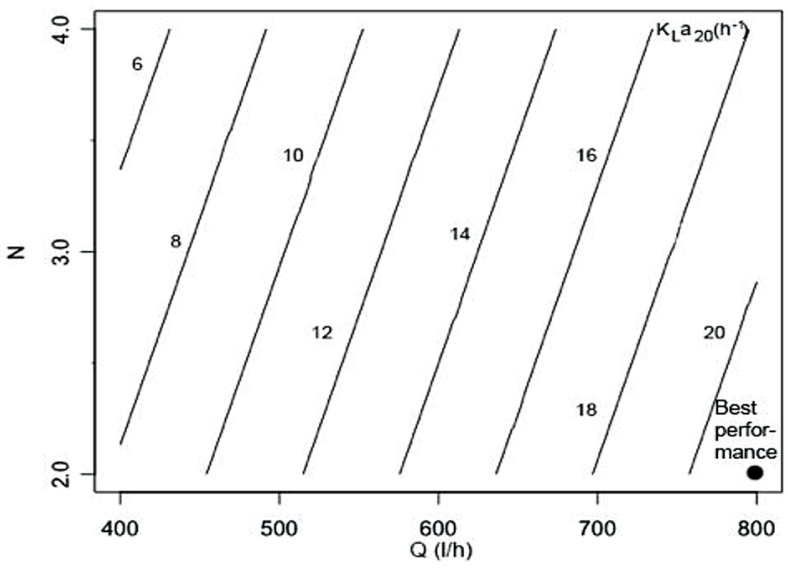

Figure 2

$K_{L} a_{20}$ response curve contours

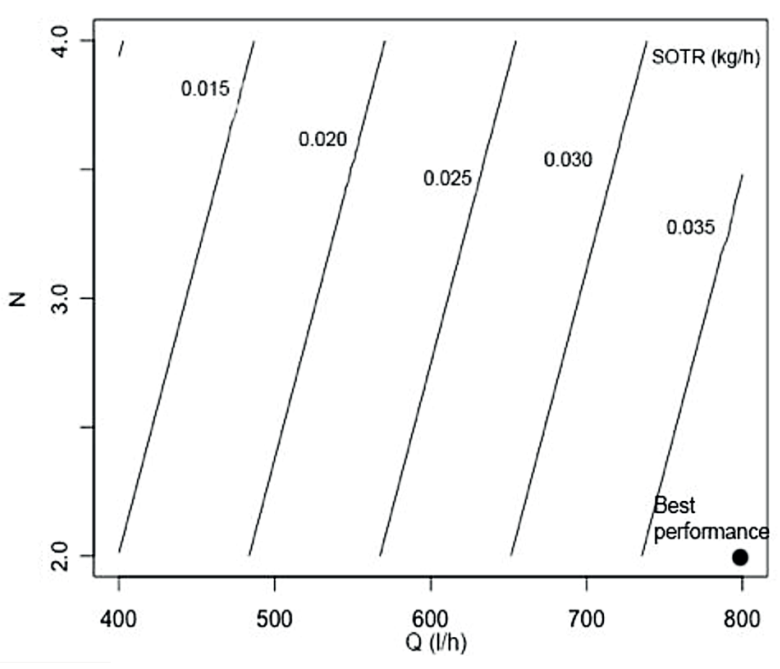

Figure 3

SOTR response curve contours

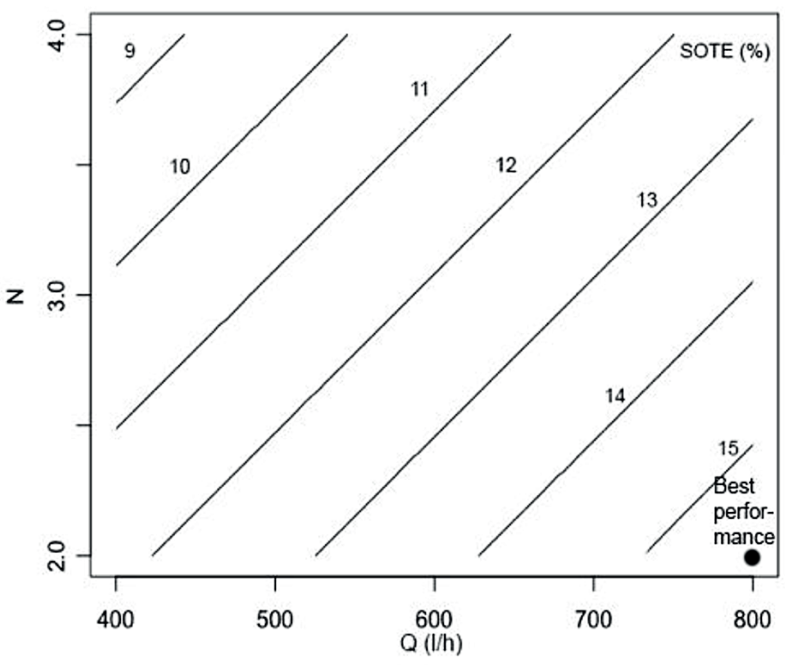

Figure 4

SOTE response curve contours

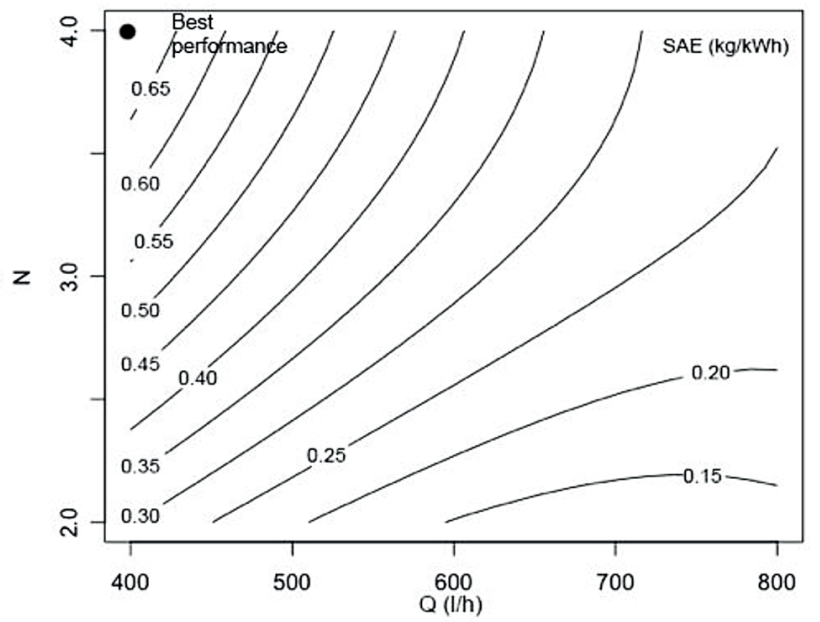

Figure 5

SAE response curve contours 
Response surface analysis helps to find points where the response variable reaches a maximum or minimum. Figures 2-5 show the location of the best performing point for each response variable. The best performing conditions found in this study lie on the edges of the investigated parameter range, meaning that optimal operating conditions likely exist outside the ranges investigated in this study.

The contours in Figs 2-5 show that both an increase in water flow rate and a decrease in the number of nozzles increase the aeration performance in terms of the volumetric $K_{\mathrm{L}} a_{20}$, SOTR and SOTE. The search for an optimal aeration device design should therefore look at systems with higher flow rates and fewer injectors operating in parallel than what was used in the current study.

The models shown in Figs $2-5$ also suggest that the driving factor behind increases in aeration performance is the power density in each injector. Increases in the flow rate in each nozzle generate a higher flow velocity and higher pressures inside the nozzles, both of which help to increase the power density inside the device. It is possible that increased power density created an environment in which smaller bubbles, or a higher number of bubbles, can be generated, which would explain the observed superior aeration performance (Ferreira et al., 2015; Linek et al., 1987)

In terms of SAE, however, Fig. 5 suggests that for a given flow rate, directing the flow of water into more nozzles increases the amount of oxygen transferred per kWh of hydraulic energy. This is plausible since air entrainment inside a given venturi nozzle depends more on water flow rate than on operating pressure. Additionally, low numbers of injectors tend to rapidly increase the operating pressure as it forces water through their narrow throat, which inhibits increases in water flow rate and, thus, in air entrainment. Higher numbers of injectors are thus more efficient since they allow water to pass more freely and entrain more air at a given water flow rate.

\section{Effect of temperature}

The results of tests performed with Aerator Design 6 at different temperatures can be found in Table 7. The obtained value for $\theta$ was 1.02 , which agrees with the generally accepted $\theta$ value of 1.024 (ASCE, 2006). Thus, it seems that the effect of temperature on the performance of the investigated aeration device is similar to what is expected for conventional aeration processes.

Based on the kinetic model of Eq. 2, it can be predicted that the volumetric transfer coefficient of venturi systems installed in cold climates would be much lower than those in warm climates. Yet, since other processes vital to wastewater treatment, such as bacterial growth rates, also vary with temperature in concert with $\mathrm{K}_{\mathrm{L}} \mathrm{a}$, and since the saturation oxygen concentration changes with temperature, more research is needed to determine whether the change in aeration performance caused by temperature would render venturi aeration impractical in some climates.

\section{Effect of TDS}

The results of the aeration tests involving changes in TDS concentration are presented in Table 8 . The t-test comparing the results of tests with low and high concentrations indicated that the variation in aeration performance caused by changes in TDS was not significant $(p>5 \%)$. The correction factor for TDS was therefore not included in the data processing of other sections of this study. This suggests that in field applications the TDS concentration of the process water may not strongly affect the efficiency or efficacy of venturi-based aeration systems.

\section{Effect of SDS}

The coefficients obtained for the linear models describing the effect of SDS on aeration performance indicators are presented in Table 9. Additionally, Fig. 6 shows the resulting linear model for $K_{L} a_{20}$ with its associated confidence interval $(\alpha=5 \%)$.

It is clear from Fig. 6 and from the values of $a_{1}$ in Table 9 that the addition of SDS to the process water increased the rate and efficiency of the oxygen transfer. The addition of $15 \mathrm{mg} / \mathrm{L}$ of SDS increased $K_{\mathrm{L}} a_{20}$ by $60 \%$ of its baseline value. Given the fact that all other operational variables besides SDS concentration were kept constant across this batch of tests, similar increases from the baseline are also observed for SOTR, SOTE, and SAE.

These results contrast with those of studies considering the effect of SDS on bubble diffuser aeration, which noted a decrease in aeration performance with the addition of

\begin{tabular}{|l|c|c|c|c|}
\hline \multicolumn{5}{|c|}{ TABLE 7 } \\
\hline $\mathrm{T}\left({ }^{\circ} \mathrm{C}\right)$ & $K_{\mathrm{L}} a\left(\mathrm{~h}^{-1}\right)$ & SOTR $(\mathrm{kg} / \mathrm{h})$ & SOTE (\%) & $\begin{array}{c}\text { SAE (kg/ } \\
\mathrm{kWh})\end{array}$ \\
\hline 10.74 & 14.23 & 0.0324 & 13.4 & 0.197 \\
\hline 10.47 & 15.24 & 0.0340 & 14.4 & 0.213 \\
\hline 20.40 & 22.05 & 0.0387 & 15.0 & 0.222 \\
\hline 20.54 & 19.48 & 0.0352 & 14.2 & 0.201 \\
\hline 30.29 & 26.18 & 0.0376 & 15.5 & 0.210 \\
\hline 30.19 & 22.18 & 0.0323 & 13.5 & 0.185 \\
\hline
\end{tabular}

\begin{tabular}{|l|c|c|c|c|}
\hline \multicolumn{5}{|c|}{$\begin{array}{c}\text { TABLE } 8 \\
\text { Comparison of Aerator Design 6's performance at } \\
\text { different TDS concentrations }\end{array}$} \\
\hline TDS (mg/L) & $\boldsymbol{k}_{\mathbf{L}} \boldsymbol{a}_{\mathbf{2 0}^{\circ} \mathrm{C}}\left(\mathbf{h}^{-1}\right)$ & SOTR $(\mathbf{k g} / \mathbf{h})$ & SOTE $(\%)$ & SAE $(\mathbf{k g} / \mathbf{k W h})$ \\
\hline 305 & 21.8 & 0.0387 & 15.0 & 0.222 \\
\hline 317 & 21.8 & 0.0391 & 15.5 & 0.218 \\
\hline 319 & 19.8 & 0.0358 & 14.8 & 0.200 \\
\hline 1277 & 21.0 & 0.0380 & 15.5 & 0.220 \\
\hline 1257 & 20.7 & 0.0375 & 14.9 & 0.212 \\
\hline$p$-value & 0.76 & $>0.99$ & 0.81 & 0.79 \\
\hline
\end{tabular}

TABLE 9

Coefficients for linear models of aeration performance with the addition of SDS (mg/L)

\begin{tabular}{|l|l|l|l|l|}
\hline Coefficient & $\boldsymbol{K}_{\mathbf{L}} \boldsymbol{a}_{\mathbf{2 0}}\left(\mathbf{h}^{-1}\right)$ & SOTR $(\mathbf{k g} / \mathbf{h})$ & SOTE (\%) & SAE $(\mathbf{k g} / \mathbf{k W h})$ \\
\hline$a_{0}$ & 21.6 & 0.0394 & 15.4 & 0.223 \\
\hline$a_{1}$ & 0.882 & 0.00165 & 0.159 & 0.00896 \\
\hline$R_{\text {Adj }}^{2}$ & 0.650 & 0.675 & 0.729 & 0.624 \\
\hline$p$-value & 0.00529 & 0.00407 & 0.00209 & 0.00692 \\
\hline
\end{tabular}




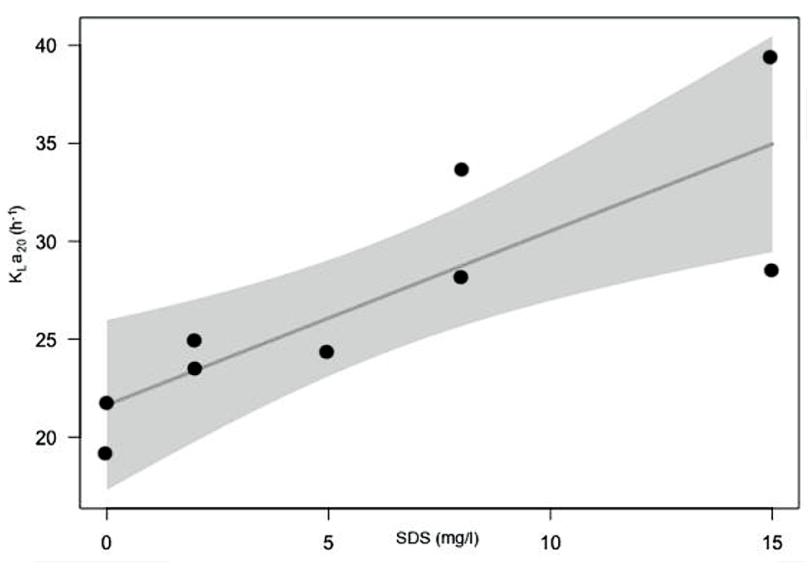

Figure 6

Linear model of the change in volumetric transfer coefficient with the addition of SDS $(\mathrm{mg} / \mathrm{L})$ with the $95 \%$ confidence interval shaded in grey (Breheny and Burchett, 2017).

surfactants (Cumby, 1987; Mancy and Okun, 1960). It has been suggested that SDS micelles create an additional stagnant film between the water and the air bubbles, and that the diffusion of oxygen through this film limits the overall transfer rate (Gujer, 2008). Additionally, it was put forward that SDS might allow small bubbles to coalesce into larger bubbles more easily, and thus reduce the volumetric interfacial area (Cumby, 1987). In the current case, however, those effects may have been counteracted by other phenomena. For example, it is possible that the foam layer that formed on the surface of the tank acted as a trap for the air bubbles, which would have increased the gas hold-up within the reactor, creating a longer opportunity window for oxygen transfer despite the lower available surface area per bubble.

Likewise, the effect observed in this study may be linked to the creation of additional turbulence at the interface between the air and the water surface caused by the gradient in surface tension created by the presence of SDS in the water (this is known as the Marangoni effect). An increase in $K_{\mathrm{L}} a$ attributable to this effect was detected at low concentrations of surfactant by Gómez-Díaz et al. in 2009 in a water- $\mathrm{CO}_{2}$ process. The detected increase of $K_{\mathrm{L}} a$ at low surfactant concentrations was followed by a sudden decrease in $K_{\mathrm{L}} a$ past a critical concentration at which the Marangoni effect was counteracted by other phenomena. It is thus conceivable that the SDS concentrations used in this study were simply lower than the critical threshold over which a decrease in $K_{\mathrm{L}} a_{20}$ might have occurred.

Some models are available in the literature to predict the effect of SDS on aeration, but they could not be used in comparison with the results of these experiments, as they include several parameters which were not measured in this study, (i.e. bubble dimensions, viscosity, surface tension). Those models also predict a negative effect of surfactants on aeration (Jamnongwong et al., 2010; Painmanakul et al., 2005); however, they do not account for the type of aerator used to form the bubbles. It is possible that SDS affects bubble formation in venturi injectors in a way that is not found in regular water jet or compressed air aeration, which would help to explain the difference between this study's results and those described in the literature.

The observed trend in aeration performance with added SDS therefore seems to suggest that the presence of surfactants in concentrations typical of domestic wastewater should not negatively affect aeration performance of venturi-based systems, and may even affect it positively in the investigated concentration range.

\section{Discussion of aerator design performance}

The largest SOTR value observed in this study was $0.037 \mathrm{~kg} / \mathrm{h}$ (Design 6). That value is quite low compared to the SOTR of mechanical aeration devices used in lagoons. For example, values of SOTR reported by Zhang et al. (2007) for that type of aerator vary from 0.15 to $0.42 \mathrm{~kg} / \mathrm{h}$, which represents a 4 - to 11 -fold increase from the current study's result. Dong et al. (2012) also found similar performances for their own venturibased apparatus ( 0.141 to $0.306 \mathrm{~kg} / \mathrm{h}$ ).

With regards to efficiency, the SAE recorded for Design 6, which had the highest volumetric transfer coefficient, is 0.21 $\mathrm{kg} / \mathrm{kWh}$. Again, this value is low compared to other types of aeration devices such as porous diffusers (typical value of 5 $\mathrm{kg} / \mathrm{kWh})$, surface turbines $(1.7 \mathrm{~kg} / \mathrm{kWh})$, vertical turbines $(1.5$ $\mathrm{kg} / \mathrm{kWh})$ and subsurface mechanical aerators $(0.9 \mathrm{~kg} / \mathrm{kWh})$ (Cumby, 1987).

It therefore seems that venturi devices perform poorly compared to other types of aerators in terms of oxygen transfer rate and efficiency. However, those alternative aeration methods all require much more equipment and specialized skills for operation and maintenance than a venturi aerator. Such additional equipment includes air compressors, mechanical stirrers, and motors. The reduced cost of purchase and maintenance of venturi aerators compared to those other options may therefore make them appealing alternatives to conventional equipment in low-resource areas, despite the increased energy consumption they entail.

Conversely, venturi nozzles are not the only low-cost, lowmaintenance systems available. For example, Cumby (1987) reports a typical SAE value for a single plunging water jet as high as $2.68 \mathrm{~kg} / \mathrm{kWh}$, which represents a 12-fold increase over this study's Design 6 and a 4-fold increase over Design 7, the most efficient design of this study. Other low-cost aeration devices should therefore be seriously considered before settling for immersed venturi-based systems. However, it is conceivable that combining plunging jets with venturi nozzles would yield good results, as Baylar and Emiroglu (2004) have found that venturi nozzles performed better than circular nozzles in plunging jet aeration tests.

\section{CONCLUSION}

Within the scope of this study, it was found that a high water flow rate combined with a low number of venturi nozzles operating in parallel generates larger oxygen volumetric transfer rates among the investigated aerator configurations. The impact of injector depth, although well documented in the literature, could not be confirmed. The effect of total dissolved solids also could not be confirmed. Moreover, it was found that the surfactant SDS increased aeration performance, contrary to what is reported in most studies evaluating the aeration performance of bubble diffusers. The influence of temperature on aeration performance was also investigated, and the measured effect was found to match what is reported in the literature. Finally, the aeration performance of the submerged venturi aerators used in this study was compared to other types of aerators, and it was found that the former perform poorly compared to mechanical aerators, porous diffusers, and 
plunging jets. More work remains to be done to characterize the impact of wastewater on venturi performance, as well as to determine whether the effects observed in this study are also found when the venturi nozzles are fitted to plunging water jets. This additional knowledge is critical to ascertain whether venturi nozzles can contribute to creating efficient and dependable wastewater treatment solutions for low-resource settings.

\section{ACKNOWLEDGEMENTS}

Authors would like to acknowledge the financial support from Grand Challenges Canada and the Humanitarian Innovation Fund. Peter Vanrolleghem holds the Canada Research Chair on Water Quality Modelling.

\section{REFERENCES}

ALI NS, MO K and KIM M (2012) A case study on the relationship between conductivity and dissolved solids to evaluate the potential for reuse of reclaimed industrial wastewater. KSCE J. Civ. Eng. 16 (5) 708-713. https://doi.org/10.1007/s12205-012-1581-x

ASCE (2006) Measurement of oxygen transfer in clean water: ASCE Standard, ASCE/EWRI 2-06, ASCE.

BAGATUR T (2005) Technical note: Minimal conditions for venturi aeration of water flows. Proc. Inst. Civil. Eng.-Water Manag 158 (3) 127-130. https://doi.org/10.1680/wama.2005.158.3.127

BAGATUR T and ONEN F (2014) A predictive model on air entrainment by plunging water jets using GEP and ANN. KSCE J. Civ. Eng. 18 (1) 304-314. https://doi.org/10.1007/s12205-013-0210-7

BAYLAR A and EMIROGLU ME (2004) An experimental study of air entrainment and oxygen transfer at a water jet from a nozzle with air holes. Water Environ. Res. 76 (3) 231-237. https://doi. org/10.2175/106143004X141780

BOX GEP (2005) Statistics for Experimenters: Design, Innovation, and Discovery, Wiley-Interscience, Hoboken, N.J.

BREHENY P and BURCHETT W (2017) Visualization of regression models using visreg. The R Journal. 9 (2) 56-71. https://cran.rproject.org/package $=$ visreg

Cumby TR (1987) A Review of Slurry Aeration 3. Performance of Aerators. J. Agr Eng. Res. 36 (3) 175-206. https://doi. org/10.1016/0021-8634(87)90073-4

DONG C, ZHU J, WU X and MILLER CF (2012) Aeration efficiency influenced by venturi aerator arrangement, liquid flow rate and depth of diffusing pipes. Environ. Technol. 33 (11) 1289-1298. https://doi.org/10.1080/09593330.2011.620986

ECKENFELDER WW, RAYMOND LW and LAURIA DT (1956) Effect of various organic substances on oxygen absorption efficiency. Sewage Ind. Waste 28 (11) 1357-1364.

FERREIRA A, TEIXEIRA JA and ROCHA F (2015) O2 mass transfer in an oscillatory flow reactor provided with smooth periodic constrictions. individual characterization of $\mathrm{kL}$ and a. Chem. Eng. J. 262 499-508. https://doi.org/10.1016/j.cej.2014.09.125
GHERNAOUT D, ALSHAMMARI Y and ALGHAMDI (2018) Improving energetically operational procedures in wastewater treatment plants. Int. J. Adv. Appl. Sci. 5 (9) 64-72. https://doi. org/10.21833/ijaas.2018.09.010

GOMEZ-DIAZ D, NAVAZA J and SANJURJO B (2009) Mass-transfer enhancement or reduction by surfactant presence at a gas-liquid interface. Ind. Eng. Chem. Res. 48 (5) 2671-2677. https://doi. org/10.1021/ie8009523

GUJER W (2008) Systems Analysis for Water Technology. Springer, Berlin, Heidelberg.

JAMNONGWONG M, LOUBIERE K, DIETRICH N and HEBRARD G (2010) Experimental study of oxygen diffusion coefficients in clean water containing salt, glucose or surfactant: consequences on the liquid-side mass transfer coefficients. Chem. Eng. J. 165 (3) 758-768. https://doi.org/10.1016/j.cej.2010.09.040

LENTH RV (2009) Response-surface methods in R, using rsm. J. Stat. Softw. 32 (7) 1-17. http://www.jstatsoft.org/v32/i07/

LINEK V, VACEK V and BENEŠ P (1987) A critical review and experimental verification of the correct use of the dynamic method for the determination of oxygen transfer in aerated agitated vessels to water, electrolyte solutions and viscous liquids. Chem. Eng. J. 34 (1) 11-34. https://doi.org/10.1016/0300-9467(87)85003-7

MANCY KH and OKUN DA (1960) Effects of surface active agents on bubble aeration. J. Water Pollut. Control Fed. 32 (4) 351-364.

MUKHTAR S, BORHAN MS, RAHMAN S and ZHU J (2010) Evaluation of a field-scale surface aeration systrem in an anaerobic poultry lagoon. Appl. Eng. Agric. 26 (2) 307-318. https://doi. org/10.13031/2013.29546

PAINMANAKUL P, LOUBIERE K, HEBRARD G, MIETTONPEUCHOT M and ROUSTAN M (2005) Effect of surfactants on liquid-side mass transfer coefficients. Chem. Eng. Sci. 60 (22) 6480-6491. https://doi.org/10.1016/j.ces.2005.04.053

R DEVELOPMENT TEAM (2016) R: A Language and Environment for Statistical Computing. R Foundation for Statistical Computing, Vienna, Austria.

SABRY T (2010) Evaluation of decentralized treatment of sewage employing upflow septic tank/baffled reactor (USBR) in developing countries. J. Hazardous Mater. 174 (1) 500-505. https://doi. org/10.1016/j.jhazmat.2009.09.080

STENSTROM MK (2012) DO-PAR. UCLA Civil and Environmental Engineering Department, Los Angeles, CA, USA.

VAN BUUREN S and GROOTHUIS-OUDSHOORN K (2011) mice: Multivariate Imputation by Chained Equations in R. J. Stat. Softw. 45 (3) 67. https://doi.org/10.18637/jss.v045.i03

YATES CN, WOOTTON BC and MURPHY SD (2012) Performance assessment of arctic tundra municipal wastewater treatment wetlands through an arctic summer. Ecol. Eng. 44 160-173. http:// dx.doi.org/10.1016/j.ecoleng.2012.04.011

ZHANG R, SUN H, KAMTHUNZI WM, COLLAR CA and MITLOEHNER FM (2007) aerator performance for wastewater lagoon application. American Society of Agricultural and Biological Engineers, 16-19 September 2007. 13. 